\title{
MECHANISMS OF MASS SPECTROMETRIC FRAGMENTATIONS: X*-INTERACTION BETWEEN REMOTE OR-GROUPS IN DECALIN-1,5-DIOLS AND THEIR DIMETHYL ETHERS
}

\author{
Hans-Friedrich Grützmacher and KarL-Heinz Fechner \\ Institut für Organische Chemie der Universität Hamburg, 2-Hamburg 13, Papendamm 6, \\ West Germany
}

(Received 17 September 1973; accepted 2 October 1973)

\begin{abstract}
The mass spectra of the five stereoisomers of decalin-1,5-diol and its dimethyl ether have been investigated. The differences in the mass spectra of stereoisomers I to III with a trans- decalin ring system are small. The differences are much larger in the mass spectra of the two isomers IV and $\mathrm{V}$ of the cis-decalin series and the elimination of $\mathrm{CH}_{2} \mathrm{O}$, formed by interaction between the two methoxy groups, from the molecular ion is only observed in the mass spectrum of $\mathrm{Vb}$.
\end{abstract}

ThE INTENSITY variation of $\left[\mathrm{M}-\mathrm{H}_{2} \mathrm{O}\right]^{+\cdot},\left[\mathrm{M}-\mathrm{CH}_{3} \mathrm{OH}\right]^{+\cdot}$ and $\left[\mathrm{M}-\mathrm{CH}_{2} \mathrm{O}\right]^{+\cdot} \cdot$ ions in the mass spectra of decalin-1,5-diol stereoisomers and the corresponding dimethyl ethers ${ }^{1}$ follows the rules connecting molecular geometry and steric control of mass spectrometric eliminations, which have been observed in the mass spectra of monocyclic diols and their dimethyl ethers. ${ }^{2,3}$ We now wish to report the observation of steric effects in the mass spectra of certain stereoisomers of decalin-1,5-diol derivatives, in which both OR groups are substituted at different rings of the molecule. A

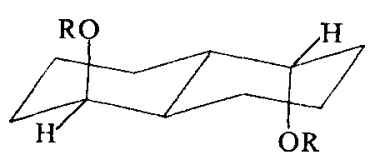

(Ia and Ib)

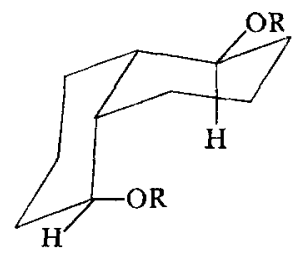

(IVa and IVb)

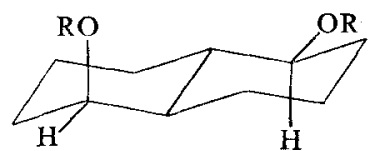

(IIa to IIc)

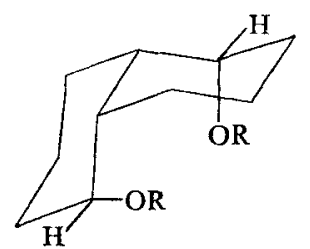

(Va to $\mathrm{Vc}$ )

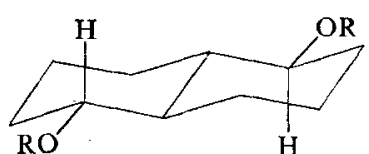

(IIIa and IIIb)

(a) $\mathrm{R}=\mathrm{H}$

(b) $\mathrm{R}=\mathrm{CH}_{3}$

(c) $\mathrm{R}=\mathrm{CD}_{3}$

mixture of stereoisomeric diols (Ia to $\mathrm{Va}$ ), obtained by catalytic hydrogenation (Raney- $\mathrm{Ni}, 170^{\circ} \mathrm{C}, 150 \mathrm{~atm} \mathrm{H}_{2}$ ) and vacuum distillation of the reaction product, was separated into the individual stereoisomers by column chromatography on silica gel (benzene/acetone in various amounts) with a purity greater than $90 \%$. The stereoisomers were identified by n.m.r. spectra and gas chromatographic retention times. ${ }^{4.5}$ The mass spectra of the free diols (Ia to Va) were obtained by direct insertion into a

* For Part IX, see Ref. 1. 
Varian MAT SM-1B mass spectrometer (ion source temp. $120^{\circ} \mathrm{C}$, electron energy $70 \mathrm{eV})$.

The diols were converted into the corresponding dimethyl ethers ( $\mathrm{Ib}$ to $\mathrm{Vb}$ ) and bistrideuteromethyl ethers (IIc and Vc) by standard procedures, and the mass spectra of these volatile derivatives were obtained by g.c./m.s. with a Varian MAT CH-4 instrument (ion source temp. $150^{\circ} \mathrm{C}$, electron energy $70 \mathrm{eV}$ ). The prominent peaks of the spectra are given in Table 1. In the absence of any experiments with derivatives isotopically labelled at the decalin ring system, no details of the fragmentation mechanisms can be given. However, the genesis of the fragment ions can be easily imagined by analogy with the mass spectrometric fragmentations of monocyclic diols, decalin-1,4-diols and their derivatives. ${ }^{1,2,3}$ The intensities of the molecular ions are surprisingly large, even in the series of dimethyl ethers. In the series of cyclic diols large molecular ion peaks have only been observed in the mass spectra of 1,2-diols, where cleavage of the $\mathrm{C}-\mathrm{C}$ bond of the glycol group results in modified molecular ions with stabilisation of the positive charge and the radical electron by adjacent OR groups. In the molecular ions of decalin-1,5-diol a similar stabilisation can be achieved by double bond cleavages:<smiles>[R]OC1CCCCC12CCCCC2[R]</smiles><smiles>[R20]CCCCC=CCCC=[R]</smiles>

TABLE 1. INTENSITIES OF CHARACTERISTIC IONS IN THE MASS SPECTRA OF DECALIN-1,5-Diols AND THEIR DIMETHYL ETHERS (BASE PEAK UNDERLINED) $\% \Sigma_{39}$

\begin{tabular}{|c|c|c|c|c|c|c|}
\hline$m / e$ & Ion & (Ia) & (IIa) & (IIIa) & (IVa) & $(\mathrm{Va})$ \\
\hline 170 & {$[\mathrm{M}]^{+}$} & 43,5 & 48,5 & 80,0 & 18,7 & 77,0 \\
\hline 152 & {$\left[\mathrm{M}-\mathrm{H}_{2} \mathrm{O}\right]^{+}$} & 43,0 & 32,6 & $\overline{30,3}$ & 42,4 & 48,7 \\
\hline 134 & {$\left[\mathrm{M}-2 \mathrm{H}_{2} \mathrm{O}\right]^{+}$.} & $\underline{77,7}$ & 88,2 & 50,9 & 55,4 & 105,2 \\
\hline 123 & $\mathrm{C}_{9} \mathrm{H}_{15}$ & $\overline{19,9}$ & $\overline{18,3}$ & 12,5 & 18,1 & 14,9 \\
\hline 121 & $\mathrm{C}_{9} \mathrm{H}_{13}$ & 8,8 & 11,9 & 14,7 & 9,0 & 16,9 \\
\hline 119 & $\mathrm{C}_{9} \mathrm{H}_{11}$ & 15,0 & 16,3 & 12,2 & 11,8 & 15,9 \\
\hline 111 & $\mathrm{C}_{7} \mathrm{H}_{10} \mathrm{OH}$ & 30,0 & 35,3 & 38,4 & 22,6 & 23,6 \\
\hline 108 & $\mathrm{C}_{8} \mathrm{H}_{12}$ & 49,2 & 64,0 & 62,0 & 42,4 & 112,4 \\
\hline \multirow[t]{2}{*}{84} & $\mathrm{C}_{5} \mathrm{H}_{7} \mathrm{OH}$ & 22,3 & 33,0 & 27,3 & $\underline{130,0}$ & 20,3 \\
\hline & & (Ib) & (IIb) & (IIIb) & (IVb) & $(\mathrm{Vb})$ \\
\hline 198 & {$[\mathbf{M}]^{+\cdot}$} & 19,1 & 11,1 & 16,8 & 5,1 & 7,0 \\
\hline 168 & {$\left[\mathrm{M}-\mathrm{CH}_{2} \mathrm{O}\right]^{+}$} & 0 & 0 & 0 & 1,3 & 10,0 \\
\hline 166 & {$\left[\mathrm{M}-\mathrm{CH}_{3} \mathrm{OH}\right]^{+}$} & 15,9 & 13,6 & 15,2 & 18,3 & 14,5 \\
\hline 136 & {$\left[168-\mathrm{CH}_{2} \mathrm{O}\right]^{+}$} & 1,3 & 1,3 & 1,0 & 2,0 & 8,9 \\
\hline 134 & {$\left[\mathrm{M}-2 \mathrm{CH}_{3} \mathrm{OH}\right]^{+}$} & 28,6 & 30,3 & 25,3 & 21,3 & 17,9 \\
\hline 125 & $\mathrm{C}_{7} \mathrm{H}_{10} \mathrm{OCH}_{3}$ & 26,7 & 24,7 & 28,6 & 19,0 & 19,4 \\
\hline 119 & $\mathrm{C}_{9} \mathrm{H}_{11}$ & 9,5 & 11,6 & 10,1 & 10,9 & 7,5 \\
\hline 111 & $\mathrm{C}_{6} \mathrm{H}_{8} \mathrm{OCH}_{3}$ & 26,7 & 22,7 & 26,9 & 24,5 & 22,1 \\
\hline 108 & $\mathrm{C}_{8} \mathrm{H}_{12}$ & 14,0 & 5,3 & 13,1 & 8,3 & 12,2 \\
\hline 98 & $\mathrm{C}_{5} \mathrm{H}_{7} \mathrm{OCH}_{3}$ & 20,4 & 37,4 & 19,4 & $\underline{78,7}$ & 54,0 \\
\hline 84 & $\mathrm{C}_{4} \mathrm{H}_{8} \mathrm{OCH}_{3}$ & 68,6 & 64,6 & 56,4 & $\overline{57,9}$ & $\underline{94,0}$ \\
\hline 71 & $\mathrm{C}_{3} \mathrm{H}_{4} \mathrm{OCH}_{3}$ & $\underline{75,0}$ & $\underline{75,7}$ & 86,4 & 74,1 & $\overline{79,9}$ \\
\hline
\end{tabular}


A synchronous cleavage of the two bonds may be supported by equatorial orientations of both OR groups, analogous to a Grob fragmentation. ${ }^{6}$ This would account for the particularly large intensities of the $m / e 170$ ions in the mass spectra of IIIa and Va. However, this effect is absent in the mass spectra of the corresponding dimethyl ethers (IIIb and $\mathrm{Vb}$ ).

The two OR groups are held apart by the rigid bicyclic system in the transdecalin-1,5-diols (Ia to IIIa) and the dimethyl ethers (Ib to IIIb). Consequently, fragmentation by interaction between both OR groups is not possible and the mass spectra of these stereoisomers are fairly similar. In the cis-isomer (IVa) and its dimethyl ether (IVb) however, one of the OR groups can approach the $\mathrm{H}$ atom of the second carbinol group, because this $\mathrm{H}$ atom and the OR group point into the hollow of the concave molecule. The dissociation energy of a $\mathrm{C}-\mathrm{H}$ bond of a carbinol group is about $20 \mathrm{kcal} / \mathrm{mol}$ less than for a normal $\mathrm{C}-\mathrm{H}$ bond: $:^{7}$ therefore $\mathrm{IVa}$ and $\mathrm{IVb}$ may be expected to lose $\mathrm{H}_{2} \mathrm{O}$ and $\mathrm{CH}_{3} \mathrm{OH}$ easily, respectively, by transfer of the carbinol $\mathrm{H}$ atom to the OR group. However, this effect is not accompanied by an increased intensity of the corresponding fragment ions, and as appropriate deuterated derivatives are not available, a 'hidden stereochemistry'8 of this elimination reaction cannot be detected.

In one of the conformations of stereoisomer $\mathrm{V}$ both OR groups approach each other in the hollow of the molecule. This is a favourable steric situation for $\mathrm{H}_{2} \mathrm{O}$ elimination from the molecular ions of $\mathrm{Va}$ by interaction between both $\mathrm{OH}$ groups, and $\mathrm{CH}_{2} \mathrm{O}$ from the molecular ions of $\mathrm{Vb}$ by interaction between both $\mathrm{OCH}_{3}$ groups. Again the amount of pure $\mathrm{Va}$ isolated from the mixture was too small to allow any labelling experiments. However, metastable transitions show that the $\left[\mathrm{M}-\mathrm{H}_{2} \mathrm{O}\right]^{+}$. ions are precursor ions for most of the other fragment ions, and the differences between the mass spectra of IVa and Va probably indicate a different structure for the $\left[\mathrm{M}-\mathrm{H}_{2} \mathrm{O}\right]^{+\cdot}$ ions of both compounds. In the case of the dimethyl ether $\mathrm{Vb}$ a distinct $\left[\mathrm{M}-\mathrm{CH}_{2} \mathrm{O}\right]^{+\cdot}$ ion peak is observed, which is completely shifted to [M $\left.\mathrm{CD}_{2} \mathrm{O}\right]^{+} \cdot$ in the mass spectrum of $\mathrm{Vc}$. Furthermore, $\mathrm{Vb}$ is the only isomer of the decalin-1,5-diol dimethyl ethers which fragments by this reaction. This leaves no doubt that the elimination of $\mathrm{CH}_{2} \mathrm{O}$ indeed occurs via transfer of a $\mathrm{H}$ atom from one $\mathrm{CH}_{3} \mathrm{O}$ group to the other, as it has been observed in the mass spectra of cis-cyclohexane-1,4-diol and cis-cyclohexane-1,3-diol dimethyl ether. ${ }^{3}$ This is the first example of a reactive interaction between two $\mathrm{CH}_{3} \mathrm{O}$ groups in the molecular ions of a bicyclic diol derivative in which both substituents are attached to different rings. One can expect that this reaction will also occur in certain stereoisomers of other decalindiol dimethyl ethers, if the molecular geometry allows the two $\mathrm{CH}_{3} \mathrm{O}$ groups to approach each other.

\section{REFERENCES}

1. Part IX. Mitteilung H. Fr. Grützmacher and K. H. Fechner, Org. Mass Spectrom. 7, 573 (1973).

2. H. Fr. Grützmacher and J. Winkler, Org. Mass Spectrom. 3, 1117 (1970).

3. J. Winkler and H. Fr. Grützmacher, Org. Mass Spectrom. 3, 1139 (1970).

4. H. Feltkamp and W. Kraus, Liebigs Ann. Chem. 683, 74 (1965).

5. K. H. Fechner, Dissertation, Hamburg, 1971.

6. (a) C. A. Grob and P. W. Schieß, Angew. Chem. 79, 1 (1967); (b) C. A. Grob, Angew. Chem. 81, 543 (1969).

7. R. H. Martin, F. W. Lampe and R. W. Taft, J. Amer. Chem. Soc. 88, 1353 (1966).

8. M. M. Green, R. J. Cook, J. M. Schwab and R. B. Roy, J. Amer. Chem. Soc. 92, 3076 (1970). 